\title{
Spousal violence and its determinants among married adolescent girls in Upper Egypt
}

\author{
Amira F. El-Gazzar ${ }^{*}$, Mirette M. Aziz, Heba M. Mohammed, Omaima Elgibaly and Manal M. Darwish
}

\begin{abstract}
Introduction: In Egypt, many girls are still married before the age of 18, which is a fundamental violation of the girls' human rights. Early marriage is associated with an alarmingly elevated risk of all types of intimate partner violence that have various negative consequences. The purpose of this study was to identify the predictors of exposure to spousal violence among the early married girls in rural Upper Egypt.
\end{abstract}

Methods: A household survey was carried out and covered 23 villages in Assiut and Sohag governorates reaching to a sample of 729 married girls before the age of 20. Listing and enumeration of 4 districts was done to identify the study participants. Data was collected by personal interviews using a structured questionnaire. Bivariate and stepwise regression analyses were performed to identify the predictors of exposure to spousal violence.

Results: It was found that $15.2 \%$ of the study participants were exposed to physical violence while $17.8 \%$ were exposed to sexual violence and $7.3 \%$ were exposed to both types. Girls married before the age of 18 were more exposed to spousal violence. Stepwise regression analysis found that girls' acceptance to get married was a protective factor against exposure to physical $(\beta=-1.07$, OR 0.34) and sexual $(\beta=-0.68, \mathrm{OR} 0.51)$ violence. The perceived attitude of husbands and mothers-in-law about considering wife beating "a husband's right" was found to be a risk factor of exposure to physical and sexual violence. Longer duration till the first pregnancy was also associated with more exposure to sexual violence ( $\beta=0.04$, OR 1.04).

Conclusion: Married adolescent girls (MAGs) are highly exposed to physical and sexual violence. This is mainly due to ignoring girls' preference to postpone their marriage, cultural concepts of accepting violence against women, and low sexual satisfaction. This study shows that most determinants of spousal violence were related to culture issues. Identifying these determinants is required to combat such a crucial public health problem that has serious consequences on adolescent health.

Keywords: Spousal violence, Upper Egypt, Early marriage, Married adolescent girls

\section{Introduction}

In Egypt, despite the legislation of the Child Law of 2008 which sets the minimum age of marriage at 18 years for females and males, many girls are still married before the age of 18 , which is a fundamental violation of the girls' human rights [1].

\footnotetext{
*Correspondence: amirafathy@aun.edu.eg; elgazzar44@yahoo.com Public Health \& Community Medicine, Faculty of Medicine, Assiut University, Assiut 71515, Arab Republic of Egypt
}

\section{Springer Open}

The 2014 Survey of Young People in Egypt (SYPE) revealed that $1.7 \%$ of married female youth aged $25-29$ in 2014 had been married before age $15,4.2 \%$ before age 16 , and $21.1 \%$ before age 18 which is the legal age of marriage in Egypt. Moreover, child marriage remains to be common in some parts of the country; $33.3 \%$ of married female youth aged 25-29 residing in rural Upper Egypt were married before age 18, compared to just below $10 \%$ of those in the Urban Governorates and urban Lower Egypt [2].

(c) The Author(s). 2020 Open Access This article is licensed under a Creative Commons Attribution 4.0 International License, which permits use, sharing, adaptation, distribution and reproduction in any medium or format, as long as you give appropriate credit to the original author(s) and the source, provide a link to the Creative Commons licence, and indicate if changes were made. The images or other third party material in this article are included in the article's Creative Commons licence, unless indicated otherwise in a credit line to the material. If material is not included in the article's Creative Commons licence and your intended use is not permitted by statutory regulation or exceeds the permitted use, you will need to obtain permission directly from the copyright holder. To view a copy of this licence, visit http://creativecommons.org/licenses/by/4.0/. 
Early marriage has been associated with withdrawal from school and low opportunity for employment and social mobility [3, 4]. Hence, those girls usually enter marriage with low levels of education and limited knowledge and skills needed to negotiate adult marital roles [5].

Furthermore, evidence suggests that early marriage is associated with an elevated risk of intimate partner violence [6-8]. The 2014 Egypt Demographic and Health Survey (EDHS) showed that one in four married adolescent girls (MAGs) in Egypt (15-19 years) was ever exposed to some form of spousal violence while 5.5\% were exposed to sexual violence [9]. A qualitative study among MAGs in three villages in Assiut revealed the presence of poor husband-wife communication, especially on matters related to achieving sexual satisfaction, thus leading to physical and sexual violence [10]. Moreover, a study in Iran has shown that spousal violence was significantly associated with low income, women age $\leq 20$ years, unemployment, low education, being non-pregnant and non-house owners, and rural residence [11].

Spousal violence is a major public health concern, since it is documented to be associated with poor health outcomes including injuries, sexual/reproductive health problems, anxiety, and depression [12].

While rural Upper Egypt has the highest levels of spousal violence [9], little is known about its predictors. The current study was designed and implemented to measure the extent of MAGs' exposure to physical and sexual violence in rural Upper Egypt and identify more precisely the predictors of such exposure. Results of the study would help the policy makers to design evidencebased interventions and programs to ameliorate the negative effects of early marriage on their health and that of their children.

\section{Methodology}

\subsection{Study design}

Data was collected using a household survey of married adolescent girls (MAGs) in Assiut and Sohag governorates, which are among the poorest and most conservative governorates in Egypt [13, 14]. The survey covered 23 villages in Assiut and Sohag reaching to a sample of 729. Data was collected by personal interview using a structured questionnaire after taking the consent of the girls and their husbands (when required). The study was conducted in selected rural communities of Assiut and Sohag governorates that were nominated by the health directorates in the two governorates based on the high prevalence of early marriage.

\subsection{Recruitment of the study population}

Married adolescent girls (under 20 years) who had been married for at least 3 months at the time of data collection were invited to participate in the study. Enumeration of all households in the selected communities and listing married inhabitants of these households were conducted by a trained team to identify the households with at least one MAG. The team was escorted by community outreach workers to facilitate their entry into the houses and alleviate the tension of the locals. The heads of the households were approached by the members of the enumeration and listing team asking them to list all married women in the household together with their ages and duration of marriage and data was validated using the identity cards of the listed married women. The listing process yielded only 730 MAGs, who were all included in the study rather than applying random selection. The interviews were conducted at a quiet area at the MAG's house or a place of her choice (e.g., health center) and lasted for about $1 \mathrm{~h}$. Field training of data collectors involved pilot testing of the instrument among 20 MAGs in two villages that were not selected for the study.

\subsection{Questionnaire}

All the study participants were interviewed using a structured questionnaire divided into sections covering all the variables that we hypothesized to be associated with exposure to spousal violence. The first section of the questionnaire detailed the socio-demographic characteristics. The second section assessed the practices related to asking the girls' opinion before marriage, premarital counseling, marital sexual relation, pregnancy, and delivery. The third section explored the social support to the MAGs by their husbands and mothers-in-law including her social mobility and participation in decision-making as well as the attitudes of husbands and mothers-in-law about violence as reported by the MAGs. The fourth section discussed the exposure of MAGs to physical and sexual violence in the year preceding data collection.

\subsection{Statistical analysis}

Data were analyzed using SPSS Statistics for Windows (version 21.0, NY). Descriptive analysis was performed for the participants' socio-demographic data. Frequencies of exposure to physical and sexual violence were calculated.

The MAGs were considered to be exposed to physical violence if responded "Yes" to any of the following: being slapped or having something thrown at you that could hurt you; being pushed or shoved; being hit with a fist or something else that could hurt; being kicked, dragged, or beaten up; being choked or burnt on purpose; and/or being threatened with, or actually, having a gun, knife, or other weapon used on you. While the MAGs were considered to be exposed to sexual violence if responded by "Yes" to any of the following: practicing sex against 
will, having a sexual relation when the husband was drunk or drugged, and being forced to do sexual acts that she was not comfortable with.

Decision-making index was created by using 10 questions expressing the girls' participation in taking different decisions. The response was given a score of "1" if the girl participated in the decision and " 0 " if she did not. Social mobility index was also created by using variables expressing the free mobility of the MAGs; 12 questions were used including the ability of the MAG to go to different places unescorted such as the doctor, family house, friend's house, and market. The score "1" expressed the ability to go to the place and "0" as inability to go. Cronbach's alpha for both scales was calculated as 0.7 and 0.6 respectively.

In the previous indices, an additive score was computed by summing the scores and the mean score percent was calculated as score/optimal score $\times 100$.

Reported sexual satisfaction was assessed using a single question which asks about the overall sexual satisfaction and was graded along a Likert scale ranging from 1 to 5 , where the score "1" denoted the least sexual satisfaction and the score " 5 " denoted the highest satisfaction.

$T$ test and chi-square test were used to identify the significant factors associated with exposure to physical and sexual violence. All significant variables on bivariate analysis were considered for inclusion in the backward regression analysis. $P$ value $<0.05$ was considered as significant.

\section{Results}

Table 1 shows the socio-demographic characteristics of the studied sample. The survey included 729 (324 in Assiut and 405 in Sohag) married girls. The majority got married $(89.7 \%)$ under the age of 18 . In both governorates, married girls shared similar socio-demographic characteristics. The mean age of girls was 18 years, and the husbands' mean age was $26.86 \pm 6.4$ years in Assiut and $25.69 \pm 4.5$ in Sohag with an average age difference between the husband and wife of 7-8 years. Almost all girls in both governorates were housewives. Consanguineous marriages were high among the studied group (59\% and $67 \%$ in Assiut and Sohag respectively). Overall, the educational level among Sohag girls was less than that among Assiut girls. The husband's educational status was better than their spouses. The mean duration between marriage and first pregnancy was 4.48 months for the total sample.

The norm for the studied MAGs in the early years of their marriage is to live in an extended family (the husband's family): $84 \%$ and $91.6 \%$ in Assiut and Sohag respectively.

Table 2 shows the percentage of exposure of the studied MAGs to physical and sexual violence in the last year. Exposure to physical violence was $15.2 \%$ (21.0\% in Assiut and $10.6 \%$ in Sohag), while exposure to sexual violence was slightly higher $17.8 \%$ (24.7\% in Assiut and $12.3 \%$ in Sohag).

Table 3 shows that exposure of MAGs to physical and sexual violence was significantly related to living with the husband alone, longer duration of marriage, and longer duration till the first pregnancy, while acceptance of marriage timing and sexual satisfaction were significantly associated with less exposure to both types of violence. It also shows that the agreement of the husbands and mothers-in-law that wife beating is a "husband right" was significantly associated with more exposure to physical and sexual violence. Moreover, sexual violence was significantly associated with marriage at age less than 18 while receiving pre-marital counseling was protective.

Table 4 shows that by backward regression analysis, it was found that acceptance of marriage timing, living with other family members, and sexual satisfaction were the significant protective factors against exposure to physical and sexual violence. Moreover, considering wife beating as "a husband right" was associated with more exposure to physical and sexual violence, and longer duration till first pregnancy was associated with more exposure to sexual violence.

\section{Discussion}

In Egypt, 30\% of ever-married women aged 15-49 reported having been ever subjected to at least one episode of physical, sexual, and/or emotional violence inflicted by their current or most recent spouse; however, sexual violence was only reported by $4 \%$ of the participants [9]. In Alexandria, a cross-sectional survey found that more than three-quarters of the participants (77\%) reported experiencing spousal violence. Emotional violence was the most commonly reported form $(71.0 \%)$, followed by physical $(50.3 \%)$ and sexual violence (37.1\%) [15].

Despite the fact that all married women from all age groups are at risk of spousal violence, married adolescent girls are at much higher risk of exposure to violence and its consequences [16]. In Egypt, one in every four adolescent married girls has been ever exposed to some form of spousal violence while $5.5 \%$ have been exposed to sexual violence [9].

Early marriage is still common in Upper Egypt, and most (89.7) of the participants in this study got married under the age of 18. Since the legal age of marriage in Egypt is 18 years, girls who married before completing their 18th birthday were in discordance with the law and are more liable to be exposed to spousal violence. According to our study, $15.2 \%$ of the study participants were exposed to physical violence while $17.8 \%$ were exposed to sexual violence in the last year (prior to the 
Table 1 Socio-demographic characteristics of the married adolescent girls (MAGs), Upper Egypt

\begin{tabular}{|c|c|c|c|}
\hline Variable & $\begin{array}{l}\text { Assiut } \\
N=324(\%)\end{array}$ & $\begin{array}{l}\text { Sohag } \\
N=405 \text { (\%) }\end{array}$ & $\begin{array}{l}\text { Total } \\
N=729 \text { (\%) }\end{array}$ \\
\hline \multicolumn{4}{|l|}{ Age at marriage (years) } \\
\hline$<18$ & $293(90.4)$ & $361(89.1)$ & $654(89.7)$ \\
\hline$\geq 18-20$ & $31(9.6)$ & $44(10.9)$ & $75(10.3)$ \\
\hline Mean \pm SD & $16.67 \pm 1.40$ & $16.47 \pm 1.64$ & $16.6 \pm 1.5$ \\
\hline \multicolumn{4}{|l|}{ Age at time of study } \\
\hline Mean \pm SD & $18.33 \pm 1.32$ & $18.47 \pm 1.42$ & $18.4 \pm 1.38$ \\
\hline \multicolumn{4}{|l|}{ Duration of marriage (months) } \\
\hline Mean \pm SD & $19.2 \pm 13.9$ & $23.5 \pm 17.0$ & $21.6 \pm 15.9$ \\
\hline \multicolumn{4}{|l|}{ Girls educational level } \\
\hline Illiterate & $21(6.5)$ & $81(20.0)$ & $102(13.9)$ \\
\hline Basic education & $89(27.5)$ & $143(35.3)$ & $232(31.8)$ \\
\hline Secondary education & $121(37.3)$ & $127(31.4)$ & $248(34.0)$ \\
\hline > Secondary education & $93(28.7)$ & $54(13.3)$ & $147(20.3)$ \\
\hline \multicolumn{4}{|l|}{ Work status } \\
\hline Work for cash & $6(1.9)$ & $2(0.5)$ & $7(1.0)$ \\
\hline Not working & $318(98.1)$ & 403(99.5) & $721(99.0)$ \\
\hline \multicolumn{4}{|l|}{ Parity } \\
\hline 0 & $180(55.6)$ & $217(53.6)$ & $397(54.5)$ \\
\hline 1 & $119(36.7)$ & $133(32.8)$ & $252(34.6)$ \\
\hline 2 & $25(7.7)$ & $46(11.4)$ & $71(9.7)$ \\
\hline 3 & $0(0)$ & $9(2.2)$ & $9(1.2)$ \\
\hline \multicolumn{4}{|c|}{ Duration of marriage till first pregnancy $\boldsymbol{n}=\mathbf{5 2 1}$ (247 Assiut, 274 Sohag) } \\
\hline Mean \pm SD & $4.05 \pm 5.9$ & $5.2 \pm 8.1$ & $4.6 \pm 7.1$ \\
\hline \multicolumn{4}{|l|}{ Husband age } \\
\hline Mean \pm SD & $26.86 \pm 6.4$ & $25.69 \pm 4.5$ & $26.2 \pm 5.4$ \\
\hline \multicolumn{4}{|l|}{ Husband education } \\
\hline Illiterate & $17(5.3)$ & $40(9.9)$ & $57(7.8)$ \\
\hline Basic education & $44(13.6)$ & $76(18.8)$ & $120(16.5)$ \\
\hline Secondary education & $26(8.0)$ & $52(12.8)$ & $78(10.7)$ \\
\hline$>$ Secondary education & $237(73.1)$ & $237(58.5)$ & $474(65.0)$ \\
\hline \multicolumn{4}{|l|}{ Consanguineous marriage } \\
\hline Yes & $189(58.3)$ & $260(64.2)$ & $449(61.6)$ \\
\hline No & $135(41.7)$ & $145(35.8)$ & $280(38.4)$ \\
\hline \multicolumn{4}{|l|}{ Co-residence } \\
\hline Lives with husband alone & $52(16.0)$ & $34(8.4)$ & $86(11.8)$ \\
\hline Lives with others & $272(84.0)$ & $371(91.6)$ & $643(88.2)$ \\
\hline
\end{tabular}

year of data collection). This percentage would have been definitely higher if we asked about exposure throughout the marital life.

Our study showed that spousal violence was associated with various cultural factors. In many cultures, it is acceptable for men to control their wives' behavior and those women who refuse may be punished.
Studies found that violence is frequently viewed as the husband's right to discipline his wife [17]. Moreover, a study conducted between 1998 and 2001 from seven countries found that male acceptance of wife beating ranged from $26 \%$ in Kazakhstan to $56 \%$ in Turkey [18]. As shown in our study, male attitudes condoning partner violence is a crucial predictor of 
Table 2 Exposure of the married adolescent girls (MAGs) to physical and sexual violence, Upper Egypt

\begin{tabular}{|c|c|c|c|}
\hline \multirow[t]{2}{*}{ Types of violence } & \multirow{2}{*}{$\begin{array}{l}\text { Assiut } \\
N=324(\%)\end{array}$} & \multirow{2}{*}{$\begin{array}{l}\text { Sohag } \\
N=405\end{array}$} & \multirow[t]{2}{*}{$N=729(\%)$} \\
\hline & & & \\
\hline \multicolumn{4}{|l|}{ Physical violence } \\
\hline Exposed & $68(21.0)$ & 43(10.6) & $111(15.2)$ \\
\hline Non-exposed & $256(79.0)$ & $362(89.4)$ & $618(84.8)$ \\
\hline \multicolumn{4}{|l|}{ Sexual violence } \\
\hline Exposed & $80(24.7)$ & $50(12.3)$ & $130(17.8)$ \\
\hline Non-exposed & $244(75.3)$ & $355(87.7)$ & $599(82.2)$ \\
\hline Exposed to both physical and sexual violence & $35(10.8)$ & $18(4.4)$ & $53(7.3)$ \\
\hline
\end{tabular}

exposure to physical and sexual violence. This was consistent with various studies where men who justified wife beating and held more gender inequitable attitudes were more likely to abuse their wives $[19,20]$.

Taking the girls' acceptance about the timing of getting married and the person she will marry not only is a human right, but also significantly affects her exposure to physical and sexual violence. Multivariable logistic regression analysis in our study showed that girls' acceptance of the marriage timing was a significant protective factor against exposure to physical and sexual violence. This was consistent with a study conducted in Turkey to identify factors associated with domestic violence. The study found that the prevalence of domestic violence was significantly lower among women whose marriage was by mutual agreement [21]. This is probably due to the similarity between the Egyptian and Turkish culture, as usually the spouses will have no chance to know each other before getting married. Moreover, women especially MAGs that are forced to get married are mostly those without economic independence and thus are less able to overcome violence.

It is common in rural Upper Egypt for married couples to live in extended families specially married adolescent girls, $88.2 \%$ of our study sample lived in extended families. The extended family can significantly affect the marital relationship of a couple, especially in the early years of their marriage, and can play a positive as well as a negative role. Bivariate and multivariable logistic regression analyses in our study showed that exposure of MAGs to physical and sexual violence was significantly associated with living with the husband alone while living with other family members was a significant protective factor against exposure to physical and sexual violence. Consistent with our study, a qualitative study done in Pakistan and the UK indicated that the husband's family can have a positive effect by minimizing conflict through offering the couple personal time and helping the wife to adjust to her new family and the wife's family could contribute by helping their daughter to adjust to her new extended family [22].
Moreover, a study done in Jordan to identify the role of the extended family on women's risk of intimate partner violence using mixed-methods study found that residence with the respondent's in-laws act as a protective factor against conflict and intimate partner violence between a husband and wife [23]. However, some studies found that a wife's in-laws act as instigators of conflict between husband and wife or a direct source of conflict with the wife and thus contributing to violence even if they do not live with or were near the couple [24, 25]. In addition, the focus group discussions (FGDs) of a study done in Jordan revealed that families were not always an effective source of assistance [23].

Sexual satisfaction is an integral part of marital life that affects the couple's relationship [26]. Our study found a significant association between violence and reported sexual satisfaction; the higher the sexual satisfaction score of the MAG, the less was the exposure to physical and sexual violence. Previous studies have repeatedly shown this association between sexual satisfaction and spousal violence. Ulloa and Hammett [27] reported a negative correlation between intimate partner violence and satisfaction. Also, a study conducted in Iran showed a significant association between partner violence and all aspects of women's sexual function [28].

The norm of Egyptian society is not postponing pregnancy of the first child especially in rural communities. Failure to conceive directly after marriage affects the psychological state of the husband, which leads to violence. Violence against women experiencing delayed pregnancy is an important health problem with serious consequences for their physical and mental health [29]. Our study revealed that longer duration till having the first baby was associated with more exposure to sexual violence.

Consistent with our study, a systematic review on the relationship between infertility, sub-fertility, and intimate partner violence found that infertility (inability to become pregnant)/sub-fertility (inability to maintain a pregnancy) are associated with violence in low- and middle-income countries [30]. Moreover, many studies found that fertility and sub-fertility could be risk factors 
Table 3 Factors affecting exposure of married adolescent girls (MAGs) to physical and sexual violence, Upper Egypt

\begin{tabular}{|c|c|c|c|c|}
\hline \multirow[t]{2}{*}{ Variables } & \multicolumn{2}{|c|}{ Physical violence } & \multicolumn{2}{|c|}{ Sexual violence } \\
\hline & Exposed & Non-exposed & Exposed & Non-exposed \\
\hline \multicolumn{5}{|l|}{ Age at marriage (years) } \\
\hline Below 18 & $101(15.4)$ & $553(84.6)$ & $124(19.0)^{*}$ & $530(81.0)$ \\
\hline 18 and above & $10(13.3)$ & $65(86.7)$ & $6(8.0)$ & $69(92.0)$ \\
\hline \multicolumn{5}{|l|}{ Girls' education } \\
\hline Illiterate & $16(76.2)$ & $5(23.8)$ & $7(33.3)$ & $14(66.7)$ \\
\hline Lower than secondary education & $169(80.5)$ & $41(19.5)$ & $58(27.6)$ & $152(72.4)$ \\
\hline Secondary education and above & $71(76.3)$ & $22(23.7)$ & $15(16.1)$ & $78(83.9)$ \\
\hline \multicolumn{5}{|l|}{ Parity } \\
\hline Mean \pm SD & $1.1 \pm 0.7$ & $1.0 \pm 0.4$ & $1.2 \pm 0.6$ & $1.0 \pm 0.5$ \\
\hline \multicolumn{5}{|l|}{ Husband's age } \\
\hline Mean \pm SD & $26.6 \pm 3.9$ & $26.9 \pm 6.8$ & $26.0 \pm 4.4$ & $27.2 \pm 6.9$ \\
\hline \multicolumn{5}{|l|}{ Husband's education } \\
\hline Illiterate & $6(35.3)$ & 11 & $5(29.4)$ & $12(70.6)$ \\
\hline Lower than secondary education & $19(27.1)$ & 51 & $23(32.9)$ & $47(67.1)$ \\
\hline Secondary education and above & $43(18.1)$ & 194 & $52(21.9)$ & $185(78.1)$ \\
\hline \multicolumn{5}{|l|}{ Consanguineous marriage } \\
\hline Yes & $40(21.2)$ & $149(78.8)$ & $50(26.5)$ & $139(73.5)$ \\
\hline No & $27(20.6)$ & $104(79.4)$ & $29(22.1)$ & $102(77.9)$ \\
\hline \multicolumn{5}{|l|}{ Co-residence } \\
\hline Living with husband alone & $26(30.2)^{* * *}$ & $60(69.8)$ & $25(29.1)^{* *}$ & $61(70.9)$ \\
\hline Living with others & $85(13.2)$ & $558(86.8)$ & $105(16.3)$ & $538(83.7)$ \\
\hline \multicolumn{5}{|l|}{ Pre-marital factors } \\
\hline \multicolumn{5}{|c|}{ Girl's opinion about timing of marriage } \\
\hline Agree & $61(11.5)^{* * *}$ & $471(88.5 \%)$ & $75(14.1)^{* * *}$ & $457(85.9)$ \\
\hline Disagree & $50(25.4)$ & $147(74.6)$ & $55(27.9)$ & $142(72.1)$ \\
\hline \multicolumn{5}{|l|}{ Receiving pre-marital counseling } \\
\hline Received & $27(12.2)$ & $194(87.8)$ & $27(12.2)^{* *}$ & $194(87.8)$ \\
\hline Not received & $84(16.5)$ & $424(83.5)$ & $103(20.3)$ & $405(79.7)$ \\
\hline \multicolumn{5}{|l|}{ Marital factors } \\
\hline \multicolumn{5}{|l|}{ Duration of marriage (months) } \\
\hline Mean \pm SD & $25.3 \pm 17.4^{* *}$ & $20.9 \pm 15.5$ & $25.1 \pm 16.8^{* *}$ & $20.8 \pm 15.6$ \\
\hline \multicolumn{5}{|c|}{ Duration of marriage till the first pregnancy (months) } \\
\hline Mean \pm SD & $6.2 \pm 8.1^{*}$ & $4.4 \pm 6.9$ & $6.97 \pm 9.8^{* * *}$ & $4.1 \pm 6.3$ \\
\hline \multicolumn{5}{|c|}{ Perceived husband's attitude towards wife beating } \\
\hline Agree & $91(20.8)^{* * *}$ & $346(79.2)$ & $92(21.1)^{* *}$ & $345(78.9)$ \\
\hline Disagree & $20(6.8)$ & $272(93.2)$ & $38(13.0)$ & $254(87.0)$ \\
\hline \multicolumn{5}{|c|}{ Perceived mother-in-law's attitude towards wife beating } \\
\hline Agree & $82(18.8)^{* *}$ & $355(81.2)$ & $91(20.8)^{*}$ & $346(79.2)$ \\
\hline Disagree & $29(9.9)$ & $263(90.1)$ & $39(13.4)$ & $253(86.6)$ \\
\hline \multicolumn{5}{|l|}{ Sexual satisfaction score } \\
\hline Mean \pm SD & $3.96 \pm 0.9^{* * *}$ & $4.3 \pm 0.5$ & $4.1 \pm 0.89^{* *}$ & $4.31 \pm 0.53$ \\
\hline \multicolumn{5}{|l|}{ Social mobility score } \\
\hline Mean \pm SD & $0.8 \pm 1.1^{*}$ & $0.6 \pm 0.9$ & $0.7 \pm 0.96$ & $0.6 \pm 0.97$ \\
\hline
\end{tabular}


Table 3 Factors affecting exposure of married adolescent girls (MAGs) to physical and sexual violence, Upper Egypt (Continued)

\begin{tabular}{lllll}
\hline Variables & Physical violence & & \multicolumn{2}{l}{ Sexual violence } \\
\cline { 2 - 3 } & Exposed & Non-exposed & Exposed & \\
\hline $\begin{array}{l}\text { Decision-making score } \\
\quad \text { Mean } \pm S D\end{array}$ & $4.7 \pm 2.2$ & $4.6 \pm 2.1$ & $4.5 \pm 2.5$ & Non-exposed \\
\hline${ }^{* P}$ value $<0.05,{ }^{* *} P$ value $<0.01,{ }^{* * * P}$ value $<0.001$ & & &
\end{tabular}

for intimate partner violence [29-33]. Also, infertile women are exposed to higher levels of marital violence compared to fertile women [34].

\subsection{Limitations of the study}

This large survey investigated an important and relatively unspoken issue but has some limitations; If husbands and mothers-in-law were interviewed, more insight on the problem would have been given, but this was very difficult in such conservative societies. Many families denied the presence of MAGs during the listing process since the legal age of marriage in Egypt is 18 years and families of MAGs who were below 18 years might face legal penalties if the case was reported to the authorities. To overcome this challenge, the enumeration and listing team members were escorted by outreach workers from the local communities to establish rapport with the families and enable the team to clarify that the collected data will be used for scientific purpose, will never be shared with the authorities, and that the filled questionnaires will have no identifiers, will not be linked to the developed lists, and the results will be presented in an aggregate form. Moreover, the data collectors were provided with identification cards affiliated to Assiut University and copies of the Central Agency for Public Mobilization and Statistics
(CAPMAS) approval of the study to assure them that they were only research-participants.

\section{Conclusion}

Girls married before the age of 18 are exposed to spousal physical and sexual violence. Taking the girls' opinion at the time of marriage and obtaining their acceptance are protective against exposure to physical and sexual violence. Moreover, cultural beliefs that consider spousal violence acceptable defiantly increase the risk of girls being exposed to violence.

In rural communities, young girls that lived with their husbands alone were more exposed to violence, which could be attributed to their inability to be totally independent. This study clearly illustrates the need for enforcement of laws as well as raising the community awareness to delay the age of marriage and respect "the girl's will" to delay her marriage until she is more autonomous, able to participate in decision-making, and more capable of bearing other marital responsibilities. In addition, mass media campaigns and public educational sessions directed towards the elimination of gender discrimination should be widely used in order to change the cultural concepts that consider wife beating a "husband right." Incorporation of sexual counseling within the $\mathrm{MCH}$ services and making it available for couples is required to improve sexual satisfaction, conflict resolution skills, and other life skills.

Table 4 Predictors of exposure of married adolescent girls (MAGs) to physical and sexual violence, Upper Egypt

\begin{tabular}{|c|c|c|c|c|c|c|}
\hline \multirow[t]{2}{*}{ Predictors } & \multicolumn{3}{|c|}{ Exposure to physical violence } & \multicolumn{3}{|c|}{ Exposure to sexual violence } \\
\hline & $\beta$ & Odds ratio & $\mathrm{Cl}$ & $\beta$ & Odds ratio & $\mathrm{Cl}$ \\
\hline Perceived husband attitude about practicing physical violence & $0.80^{*}$ & 2.24 & $1.5-4.7$ & $0.82^{* *}$ & 2.270 & $1.4-8.2$ \\
\hline Co-residence & $-0.82^{*}$ & 0.46 & $0.1-0.78$ & $-0.75^{*}$ & 0.48 & $0.21-0.57$ \\
\hline Girl's opinion about marriage timing & $-1.07^{* * *}$ & 0.34 & $0.13-0.61$ & $-0.68^{* *}$ & 0.51 & $0.3-0.7$ \\
\hline Reported sexual satisfaction & $-0.77^{* * *}$ & 0.46 & $0.31-0.88$ & $-0.39^{*}$ & 0.68 & $0.31-0.85$ \\
\hline Duration till first pregnancy & 0.02 & 1.03 & $0.97-1.1$ & $0.04^{* *}$ & 1.04 & $1.01-1.08$ \\
\hline Duration of marriage & 0.01 & 1.01 & $0.98-1.0$ & 0.06 & 1.0 & $0.9-1.0$ \\
\hline Perceived mother-in-law's attitude about practicing physical violence & 0.07 & 0.93 & $0.71-1.2$ & 0.13 & 1.14 & $0.51-2.58$ \\
\hline Social mobility score & 0.02 & 1.02 & $0.95-1.1$ & -0.009 & 0.99 & $0.92-1.06$ \\
\hline Age at marriage (below 18) & - & - & - & 0.037 & 1.03 & $0.22-4.7$ \\
\hline
\end{tabular}

${ }^{*} P$ value $<0.05,{ }^{* *} P$ value $<0.01,{ }^{* *} P$ value $<0.001$ 


\section{Abbreviations}

MAGs: Married adolescent girls

\section{Acknowledgements}

We acknowledge the population council specifically Dr. Nahla abdel Tawab and Dr. Doaa Oraby for the logistic support during data collection of this survey as well as the married adolescent girls who volantarly participated in this survey.

\section{Authors' contributions}

OE conceived the idea of the study, wrote the protocol, supervised the data collection, and revised the questionnaire. MMD participated in designing the questionnaire, data collection, and analysis. AFE-G participated in designing the questionnaire, data collection, and analysis; wrote the "Discussion" section; and revised the final manuscript. HMM participated in designing the questionnaire, data collection, and analysis as well as writing part of the "Discussion" section. MMA participated in the data collection and analysis as well as writing the "Introduction," "Methodology," and "Results" sections. The authors read and approved the final manuscript.

\section{Funding}

This study was funded by the population council, Cairo office.

\section{Availability of data and materials}

Available on reasonable request.

\section{Ethics approval and consent to participate}

The study protocol was reviewed and approved by the Research Ethics Committee at Assiut University, Egypt, with reference no. 17300343 dated 18 May 2018. Procedures for the protection of participant confidentiality were observed. No personal identifiers were recorded on the questionnaires; identification code numbers were used instead. Information revealed by MAG was not shared with their families or members of their community. Access to research data was limited to the research staff. Due to the conservative nature of Egyptian society, especially in rural Upper Egypt, approval of an older person (e.g., head of household, mother/mother-in-law) was needed before interviewing the MAG. Permission of the guardian was sought before that of the MAG; however, the latter was notified that she was free to decline even if her guardian had agreed.

\section{Consent for publication}

No individual details, images, or videos were included in the manuscript.

\section{Competing interests}

No conflict of interest.

Received: 9 November 2019 Accepted: 15 September 2020

Published online: 13 October 2020

\section{References}

1. UNICEF. Child marriage in the Middle East and North Africa - Egypt Country Brief, United Nations Children's Fund (UNICEF), Middle East and North Africa Regional Office in collaboration with the International Center for Research on Women (IRCW). 2017. https://www.icrw.org/publications/childmarriage-in-the-middle-east-and-north-africa/.

2. Roushdy R, Maia S. Panel Survey of Young People in Egypt (SYPE): Generating evidence for policies, programs, and research. Population Council. Summary Report: Cairo; 2014.

3. Brady M, Assaad R, Ibrahim B, Salem A, Salem R, Zibani N. Providing new opportunities to adolescent girls in socially conservative settings: The Ishraq program in rural Upper Egypt, full report. New York: Population Council; 2007.

4. Raj A, Salazar M, Jackson E, Wyss N, McClendon K, Khanna A, et al. Students and brides: a qualitative analysis of the relationship between girls' education and early marriage in Ethiopia and India. BMC Public Health. 2019:19(1):1-20.

5. UNICEF. State of the World's Children: Adolescence, an age of opportunity New York: UNICEF; 2011. https://www.who.int/pmnch/media/news/2011/2 0110301_unicef_2010_stateworldchildren/en.

6. Jensen R, Thornton R. Early female marriage in the developing world. Gend Dev. 2003;11(2):9-19.
7. Hindin M, Kishor S, Ansara D. Intimate partner violence among couples in 10 DHS countries: predictors and health outcomes. Macro International: Calverton, Maryland, USA; 2008

8. Speizer I, Pearson E. Association between early marriage and intimate partner violence in India: a focus on youth from Bihar and Rajasthan. J Interpers Violence. 2011;26(10):1963-81.

9. Ministry of Health and Population [Egypt], El-Zanaty and Associates [Egypt], and ICF International. Egypt demographic and health survey 2014. Egypt and Rockville, Maryland, USA: Cairo; 2015.

10. Darwish M, Hamza W, Aziz M, El-Gazzar A. Sexual and reproductive health experiences of married adolescent girls in rural Upper Egypt". In AbdelTawab N, Saher S, El Nawawi N, Editors. Chapter 6: Breaking the silence: learning about youth sexual and reproductive health in Egypt. Cairo: Population Council; 2013.

11. Faramarzi M, Esmailzadeh S, Mosavi S. Prevalence and determinants of intimate partner violence in Babol City, Islamic Republic of Iran. East Mediterr Health J (EMHJ). 2005;11:870-9.

12. Raj A. Public health impact of marital violence against women in India. Indian J Med Res. 2019:150(6):525-31.

13. UNFPA. Localizing the targets of the sustainable development goals at governorate level. United Nation, Egypt, 2018. https://egypt.unfpa.org/en/ publications/localizing-targets-sustainable-development-goals-governoratelevel.

14. Human Development Index. List of governorates of Egypt. https://en.m. wikipedia.org/wiki/List_of_governorates_of_Egypt_by_Human_ Development_Index.

15. Mamdouh H, Ismail H, Kharboush I, Tawfik M, El Sharkawy O, Abdel Baky M, et al. Prevalence and risk factors for spousal violence among women attending health care centres in Alexandria, Egypt. East Mediterr Health J. 2012:18(11):1118-26.

16. Kidman R. Child marriage and intimate partner violence: a comparative study of 34 countries. Int J Epidemiol. 2017;46(2):662-75.

17. Heise L, Ellsberg M, Gottemoeller M. Ending violence against women. Population reports. 1999;27(4):1.

18. Rani M, Bonu S. Attitudes toward wife beating: a cross-country study in Asia J Interpers Violence. 2009:24(8):1371-97.

19. Johnson K, Das M. Spousal violence in Bangladesh as reported by men: prevalence and risk factors. J Interpers Violence. 2009;24(6):977-95.

20. Naved R, Huque H, Farah S, Shuvra M. Men's attitude and practices regarding gender and violence against women in Bangladesh: preliminary findings. Dhaka, Bangladesh 2011. [Internet]. icddr,b Special Publication No. 135. http://www.partners4prevention.org/sites/default/files/resources/final_ report_bangladesh.pdf.

21. Gokler M, Arslantas D, Unsal A. Prevalence of domestic violence and associated factors among married women in a semi-rural area of western Turkey. Pak J Med Sci. 2014;30(5):1088-93.

22. Ali $P, O^{\prime}$ Cathain $A$, Croot E. Influences of extended family on intimate partner violence: perceptions of Pakistanis in Pakistan and the United Kingdom. J Interpers Violence. 2018:1-29.

23. Clark C, Silverman J, Shahrouri M, Everson-Rose S, Groce N. The role of the extended family in women's risk of intimate partner violence in Jordan. Socl Sci Med. 2010;70(1):144-51.

24. Kapadia M, Saleem S, Karim M. The hidden figure: sexual intimate partner violence among Pakistani women. Eur J Publ Health. 2010;20(2):164-8.

25. Chan K, Tiwari A, Fong D, Leung W, Brownridge D, Ho P. Correlates of inlaw conflict and intimate partner violence against Chinese pregnant women in Hong Kong. J Interpers Violence. 2009;24(1):97-110.

26. Guo B, Huang J. Marital and sexual satisfaction in Chinese families: exploring the moderating effects. J Sex Marital Ther. 2005:31(1):21-9.

27. Ulloa $E_{1}$ Hammett J. Temporal changes in intimate partner violence and relationship satisfaction. J Fam Violence. 2015:30(8):1093-102.

28. Jamali S, Javadpour $\mathrm{S}$. The impact of intimate male partner violence on women's sexual function: a study in Iran. J Clin Diagn Res. 2016;10(12): QC29-33.

29. Aduloju P, Olagbuji N, Olofinbiyi A, Awoleke J. Prevalence and predictors of intimate partner violence among women attending infertility clinic in south-western Nigeria. Eur J Obstet Gynecol Reprod Biol. 2015;188:66-9.

30. Stellar C, Garcia-Moreno C, Temmerman M, van der Poel S. A systematic review and narrative report of the relationship between infertility, subfertility, and intimate partner violence. Int J Gynaecol Obstet. 2016; 133(1):3-8. 
31. Ardabily H, Moghadam Z, Salsali M, Ramezanzadeh F, Nedjat S. Prevalence and risk factors for domestic violence against infertile women in an Iranian setting. Int J Gynaecol Obstet. 2011;112(1):15-7.

32. Akyuz A, Seven $M$, Sahiner $G$, Bilal B. Studying the effect of infertility on marital violence in turkish women. Int J Fertil Steril. 2013;6(4):286-93.

33. Sheikhan Z, Ozgoli G, Azar M, Alavimajd H. Domestic violence in Iranian infertile women. Med J Islam Repub Iran. 2014;28:152.

34. Ameh N, Kene T, Onuh S, Okohue J, Umeora O, Anozie O. Burden of domestic violence amongst infertile women attending infertility clinics in Nigeria. Niger J Med. 2007;16(4):375-7.

\section{Publisher's Note}

Springer Nature remains neutral with regard to jurisdictional claims in published maps and institutional affiliations.

\section{Submit your manuscript to a SpringerOpen ${ }^{\circ}$ journal and benefit from:}

- Convenient online submission

- Rigorous peer review

- Open access: articles freely available online

High visibility within the field

- Retaining the copyright to your article

Submit your next manuscript at $\boldsymbol{\nabla}$ springeropen.com 